\title{
Variations of electron density and temperature in ionosphere based on the DEMETER ISL data*
}

\author{
Yufei He ${ }^{1}$ Dongmei Yang ${ }^{1, *}$ Rong Zhu ${ }^{1} \quad$ Jiadong Qian $^{2}$ and M Parrot $^{3}$ \\ ${ }^{1}$ Institute of Geophysics, China Earthquake Administration, Beijing 100081, China \\ ${ }^{2}$ Institute of Earthquake Science, China Earthquake Administration, Beijing 100036, China \\ ${ }^{3}$ Laboratoire de Physique et Chimie de l'Environment, Centre National de la Recherche Scientifique, Orleans, France
}

\begin{abstract}
Observations of the Langmuir Probe Instrument (ISL, Instrument Sonde de Langmuir) onboard the DEMETER satellite during four years from 2006 to 2009 were used to analyze the tempo-spatial variations of electron density $\left(N_{\mathrm{e}}\right)$ and temperature $\left(T_{\mathrm{e}}\right)$ in the ionosphere. Twenty four research bins with each covering an area with $10^{\circ}$ in longitude and $2^{\circ}$ in latitude were selected to study the spatial distributions of $N_{\mathrm{e}}$ and $T_{\mathrm{e}}$. The results indicate that both $N_{\mathrm{e}}$ and $T_{\mathrm{e}}$ have strong annual variations in the topside ionosphere at $660 \mathrm{~km}$ altitude. The semiannual anomaly and equinoctial asymmetry which are usually well known as the features of F-layer also exist in the topside ionosphere at low- and mid-latitudes. The yearly variation of $N_{\mathrm{e}}$ is opposite to the peak electron density of the F2-layer $(\mathrm{NmF} 2)$ at higher latitudes in daytime and both are similar in nighttime. Also the yearly variations of $T_{\mathrm{e}}$ at low-latitude are contrary to that at $600 \mathrm{~km}$ in daytime and similar in nighttime. An interesting feature of nighttime $T_{\mathrm{e}}$ at low-latitude is an obvious annual variation in the northern hemisphere and semiannual variation in the southern hemisphere. The yearly variations of $T_{\mathrm{e}}$ in daytime have negative and positive correlation with $N_{\mathrm{e}}$ at mid- and high-latitudes, respectively. Both $N_{\mathrm{e}}$ and $T_{\mathrm{e}}$ in the neighborhood bins at the same latitude have a high correlation. In ionospheric events analyzing, this information may help to understand the characteristics of the variation and to distinguish the reliable abnormality from the normal background map.
\end{abstract}

Key words: seasonal variation; annual variation; spatial distribution; $N_{\mathrm{e}} ; T_{\mathrm{e}}$; DEMETER satellite CLC number: P315.72 Document code: A

\section{Introduction}

DEMETER satellite is the first satellite, which specially serves to earthquake studying and volcanic monitoring. Its scientific goal is to detect abnormality that might exist in the ionosphere before earthquake occurrence or volcano eruption. At present, studies using the DEMETER satellite data on the anomalous phenomena in the ionosphere relating to earthquakes have been published, including case studies and statistic studies (Parrot et al, 2006; Sarkar et al, 2007; Zhu et al, 2008; Rozhnoi et al, 2008; Nemec et al, 2009; Akhoondzadeh et al, 2010). From these researches, it can be seen that the important work in extracting abnormal information is to know the variation of the ionospheric background.

Now, there are many researches reported on iono-

\footnotetext{
${ }^{*}$ Received 4 May 2009; accepted in revised form 11 June 2009; published 10 August 2010.

- Corresponding author. e-mail: ydmgeomag@263.net

(c) The Seismological Society of China and Springer-Verlag Berlin Heidelberg 2010
}

sphereic background. Both ground and space data are use (e.g. Zhao et al, 2007; Oliver et al, 2008; Liu et al, 2006, 2007a, b, 2009a, b). These studies show that the variations in ionosphere are extraordinary complicated and many anomalous structures have been explored. And the anomalies defined by the observed values were significantly deviated from the predicted solar zenith angle dependence. The main anomalies type were characterized by Zou et al (2000), including the 'winter or seasonal anomaly, which expresses the daytime values of mid-latitude NmF2 in northern hemisphere are much greater in winter than that in summer, but this anomaly disappears at night; 'semiannual anomaly' which represents the NmF2 at equinox greater than that at solstice; 'annual anomaly or non-seasonal anomaly' which describes the NmF2 (in the whole world) in December is greater than in June during both daytime and night; 'equinoctial asymmetry' which presents the electron density is higher at on equinox than that at the other. These phenomena were detected in the 1930s and most 
were described by the end of the 1950s; for historical details see Rishbeth (1998). Recent researches have shown that variations in ionosphere have a significant altitude dependency (e.g., Chen et al, 2009; Liu et al, 2007a; Balan et al, 2000; Bailey et al, 2000; Su et al, 1998), that is to say, the feature of the ionospheric variation changes with altitude.

As complexity of the ionospheric variation and the unique of measure instrument, though more studies have been done, these results cannot be directly applied to analyzing the data recorded by another instrument. In this paper, we will use $N_{\mathrm{e}}$ and $T_{\mathrm{e}}$ data from Langmuir Probe (ISL, Lebretona et al, 2005) which onboard DEMETER satellite to analyze the ionospheric variation at DEMETER orbit altitude and to provide useful information for the earthquake or volcano abnormality recognizing. At present, the DEMETER satellite has been successfully running for about six years and a large number of observation data have been accumulated. That provided a wealth of data for the background research.

Taking into account that the altitude of the DEMETER satellite orbits has been adjusted to be $660 \mathrm{~km}$ from $710 \mathrm{~km}$ in December 2005, data from January 1, 2006 to the end of 2009 was used in this paper.

\section{Data and preliminary analysis}

The French DEMETER satellite was launched on June 29,2004 . It has a nearly circular sun-synchronous orbit (10.30LT in day sector, 22.30LT in night sector).

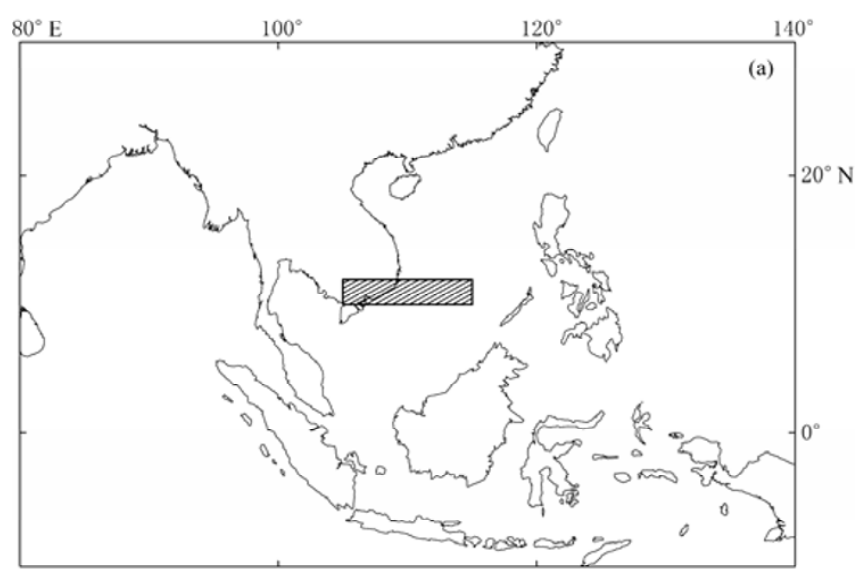

The orbital altitude is about $710 \mathrm{~km}$ (adjusted to $660 \mathrm{~km}$ at the end of 2005) and the orbital inclination is $98^{\circ}$. The scientific instruments perform measurement between $-65^{\circ}$ and $+65^{\circ}$ in geomagnetic latitude (Cussac et al, 2006). The two main parameters measured by ISL are electron density $\left(N_{\mathrm{e}}\right)$ and electron temperature $\left(T_{\mathrm{e}}\right)$. The accepted accuracy is $\pm 15 \%$ for $T_{\mathrm{e}}$ and $\pm 30 \%$ for $N_{\mathrm{e}}$ (Lebretona et al, 2005).

The orbital repeat period of DEMETER satellite is about 16 days; that is to say, the satellite will revisit the orbit once every 16 days. The distance between the adjacent orbits is about $2500 \mathrm{~km}$ at low latitudes. To make sure that the research area had observation data everyday, the $20^{\circ}$ resolution in longitude is necessary. The DEMETER satellite had a high resolution in latitude. To construct a high resolution background map, we divided the world map into $90 \times 36$ bins of $2^{\circ}$ (latitude) $\times 10^{\circ}$ (longitude). For each bin, we collected all data recorded by ISL in four years and calculated the averages by day. Then we sorted the averages by time. Thus the yearly variation of each bin was established. As limited by the size of bins, two averages can be gained about every three days. Figure 1 gives an example of the yearly variation of $N_{\mathrm{e}}$ and $T_{\mathrm{e}}$ in one bin which is located in near the geomagnetic equator $\left(10^{\circ} \mathrm{N}-12^{\circ} \mathrm{N}, 105^{\circ} \mathrm{E}-115^{\circ} \mathrm{E}\right)$. As shown in the Figures $1 \mathrm{~b}$ and $1 \mathrm{c}$, black lines are 60 days moving average and gray lines indicate the observed data in this bin. The smooth curve can represents well the feature of the variation in this bin. So in the following analysis, only the smooth data were used.

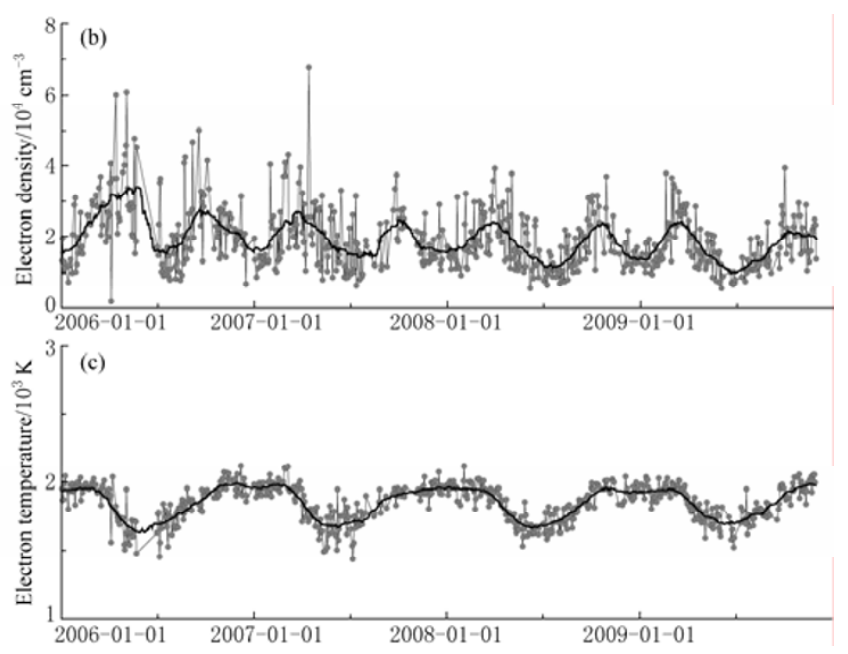

Figure 1 Locations of the research bins and the yearly variations of $N_{\mathrm{e}}$ and $T_{\mathrm{e}}$. (a) Research area represented by the shaded rectangle; (b) Yearly variation of electron density $\left(N_{\mathrm{e}}\right)$; (c) Yearly variation of electron temperature $\left(T_{\mathrm{e}}\right)$. 


\section{Results and discussion}

In this paper, five bins distributed in the same latitude and 20 bins which are located in the same longitude were selected for analysis. By comparing the variations in these bins, we hope to explore the characteristics of the tempo-spatial variation of $N_{\mathrm{e}}$ and $T_{\mathrm{e}}$.

\subsection{Spatial distribion along latitude}

For low resolution in longitude of the DEMETER satellite, it is difficult to obtain observed data in a small research region. To detect whether the adjacent orbit data can be as a proxy or not when the data is missing or there is no data, five comparable bins, labeled by ' $A$ ' to ' $E$ ' from left to right, respectively, were chosen to analyze the spatial distribution of yearly variation on the same latitude. The yearly variations of $N_{\mathrm{e}}$ and $T_{\mathrm{e}}$ in five bins are all plotted in Figure 2, which made it convenient for us to compare each other and easy to find the characteristic of distribution along latitude.
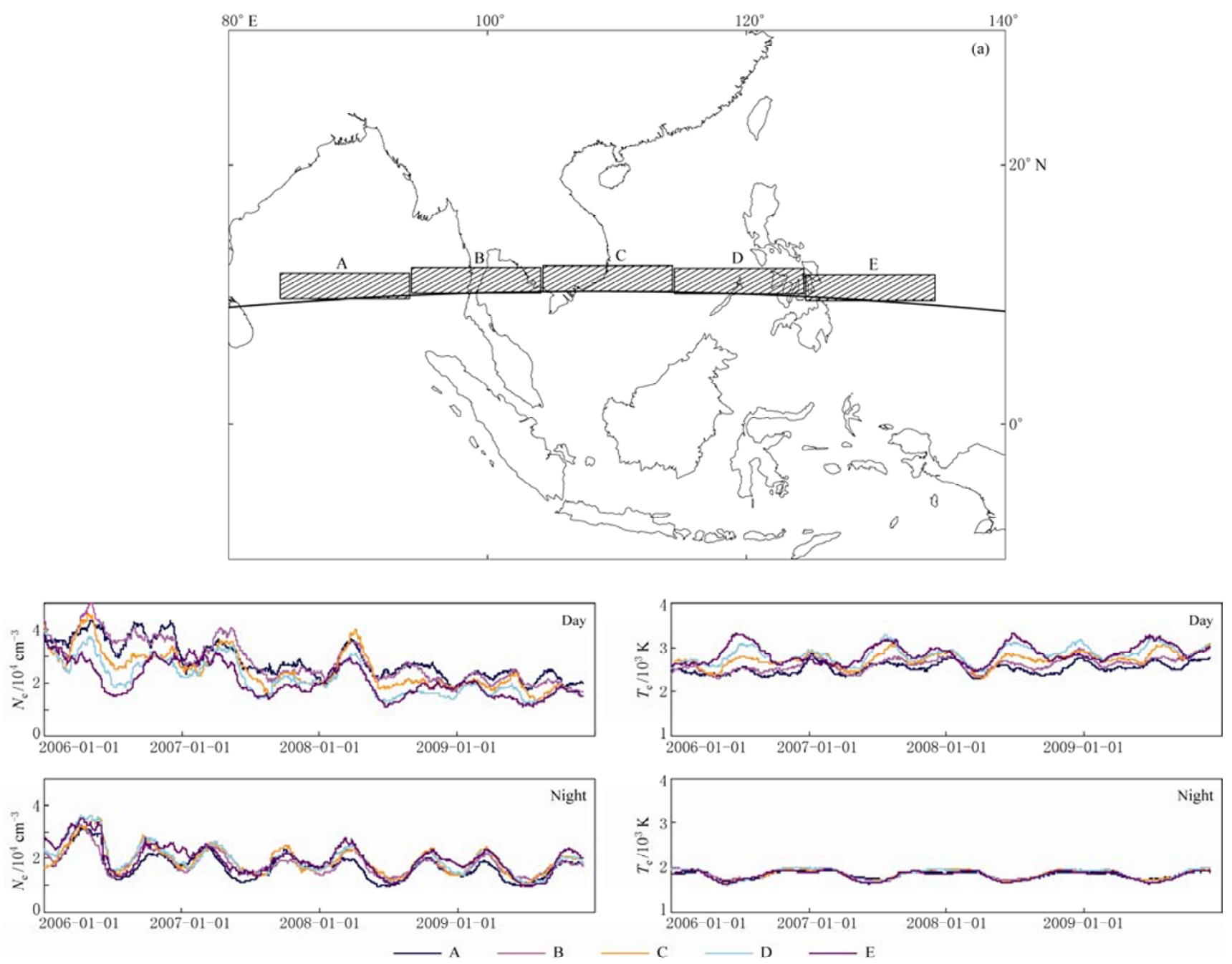

(b)

(c)

Figure 2 Locations of the five comparable bins and the yearly variations of $N_{\mathrm{e}}$ and $T_{\mathrm{e}}$. (a) Research area represented by the shaded rectangle and the black line indicates the geomagnetic equator; (b) Yearly variations of electron density; (c) Yearly variations of electron temperature.

Figures $2 \mathrm{~b}$ and $2 \mathrm{c}$ show yearly variations of $N_{\mathrm{e}}$ and $T_{\mathrm{e}}$ in comparable bins. Both yearly variations of $N_{\mathrm{e}}$ and $T_{\mathrm{e}}$ in these areas nearly show the same varying characteristics in nighttime. But they did not agree well with each other in daytime. To analyze the feature along the longitude, we calculate correlation coefficients of the yearly variation between the ' $A$ ' bins and the other four bins. The results are presented in Figure 3. The correla- 
tion coefficients of $N_{\mathrm{e}}$ and $T_{\mathrm{e}}$ gradually reduce with the distance increasing at nighttime, but they are still at a high level. While the correlation coefficients decrease rapidly at daytime. The high correlation coefficients between these bins at nighttime indicated that the data in adjacent bins at the same latitude could be used as a proxy. This result is consistent with the conclusion of Zhang's work (Zhang et al, 2008) who found that the adjacent orbit data within $2000-4000 \mathrm{~km}$ in longitude at the same latitude have a high correlation on the same day. But this result can not apply to the daytime data.
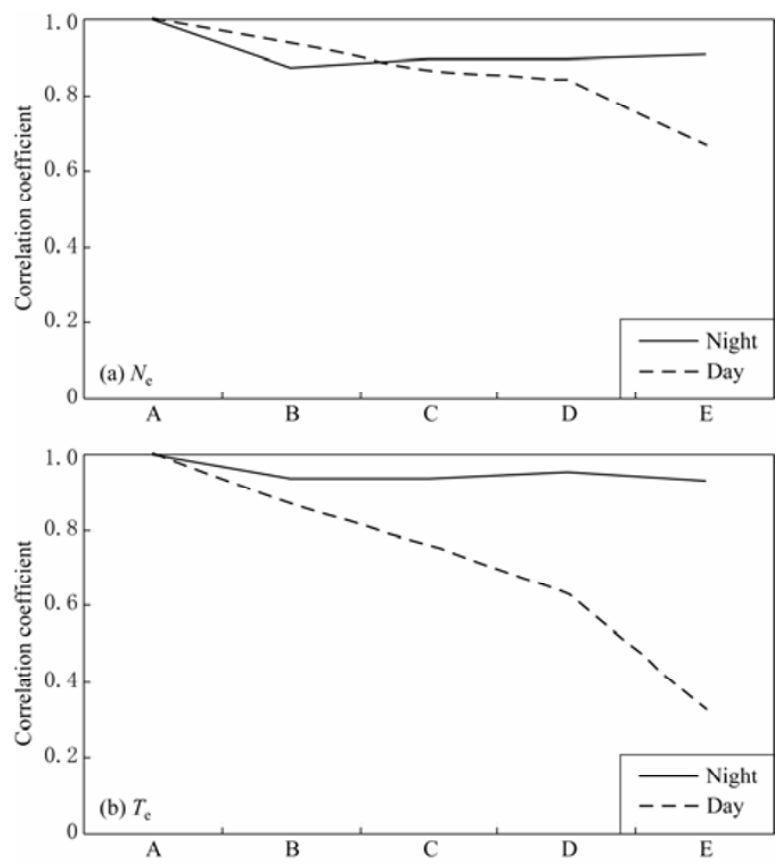

Figure 3 Correlation coefficients of electron density and electron temperature between ' $A$ ' bin and the other four bins.

\subsection{Spatial distribution along longitude}

To analyze the spatial distributions of $N_{\mathrm{e}}$ and $T_{\mathrm{e}}$ along longitude, 20 bins were selected (see Figure 4). Considering ionosphere is very dynamic at low latitudes, more bins were chosen in equator range than that in mid- and high-latitude. These bins are located in different latitude along the same geomagnetic longitude. The yearly variations of these bins are presented in Figure 5 and they are labeled by geomagnetic latitudes of these bins' center. And the analyzing results are also displayed as follows.

As shown in Figures $5 \mathrm{a}$ and $5 \mathrm{~b}$, the yearly variations of daytime $N_{\mathrm{e}}$ at mid- and low-latitudes both in northern and southern hemispheres had similar characteristic that they have maxima around the equinoxes and

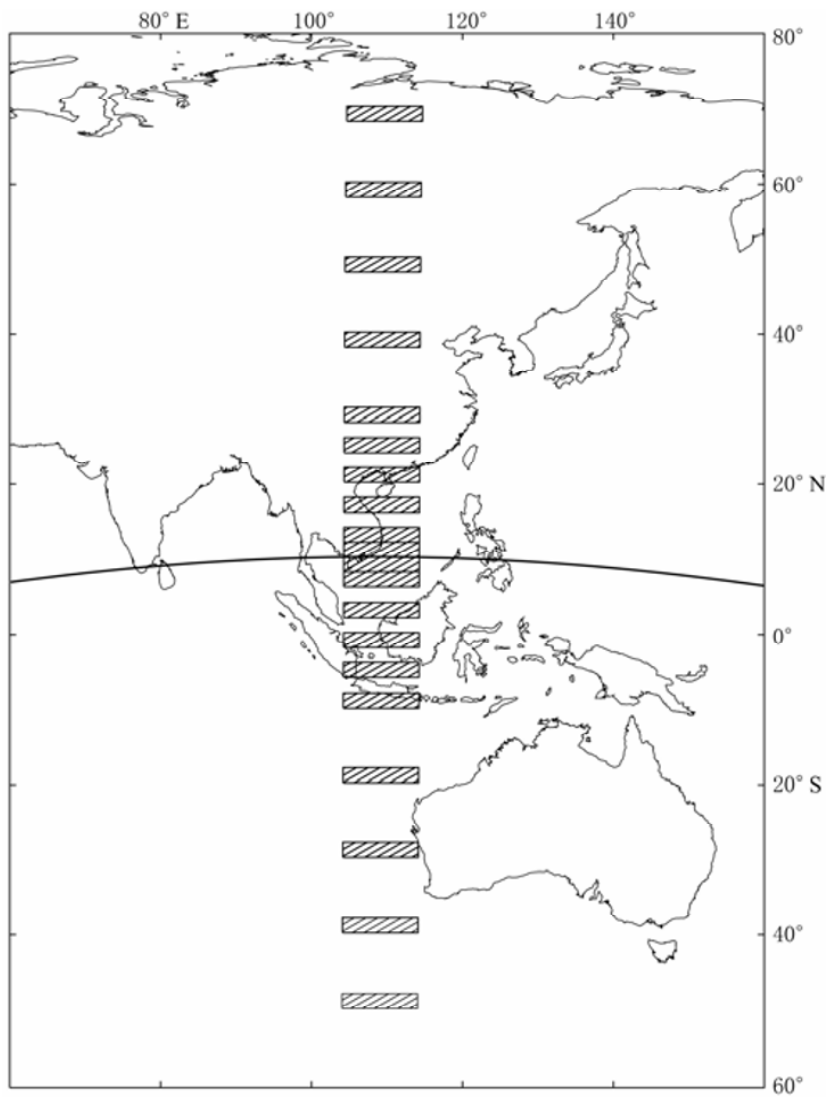

Figure 4 Locations of the selected bins represented by shaded rectangle and the solid line indicates the geomagnetic equator.

minima around the solstices in four years. This feature is the 'semiannual anomaly' which generally exists in the ionospheric F-layer (Torr and Torr, 1973). With the latitude increasing, the daytime $N_{\mathrm{e}}$ in the southern hemisphere rise much more rapidly than that in the northern hemisphere and the peaks of daytime $N_{\mathrm{e}}$ in the northern hemisphere around the March/September equinox begin to shift towards the summer. When it comes to higher latitudes, the two peaks disappeared and were replaced by one peak around July solstice. This is opposite to the $\mathrm{NmF} 2$ which has a minimum around July solstice, but the nighttime $N_{\mathrm{e}}$ in both hemispheres is similar to Zou's result (Zou et al, 2000). The 'annual anomaly' is not obviously both in the southern and northern hemispheres. The low solar activity level in the four years might be the main reason because the plasma density in the topside ionosphere is dependent on solar activity level (e.g. Liu et al, 2007a; Bailely et al, 2000; Su et al, 1998). The 'equinoctial asymmetry' also can be seen in low- and mid-latitudes where daytime $N_{\mathrm{e}}$ is higher at March equinox than at September equinox. This is consistent 


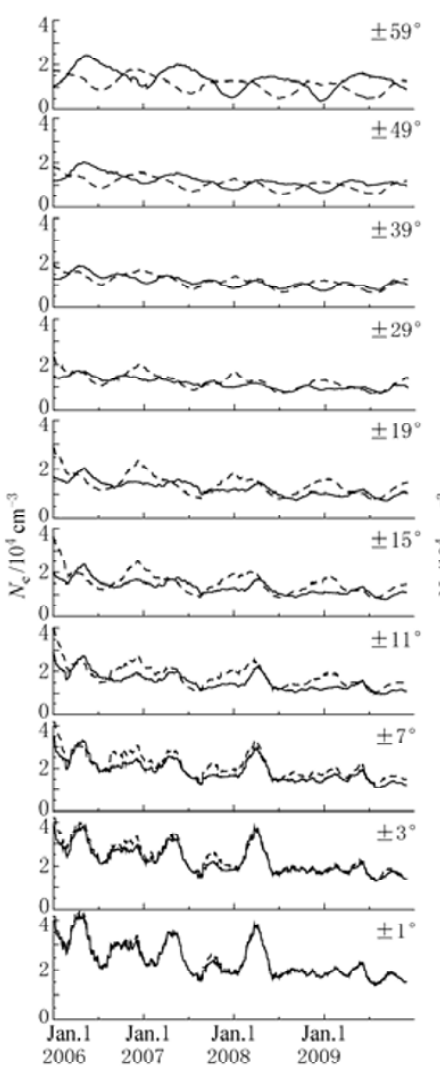

(a)

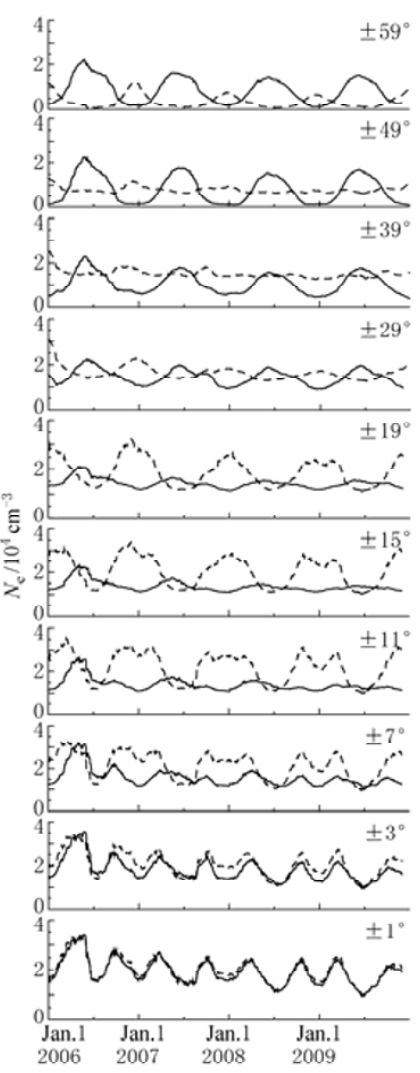

(b)

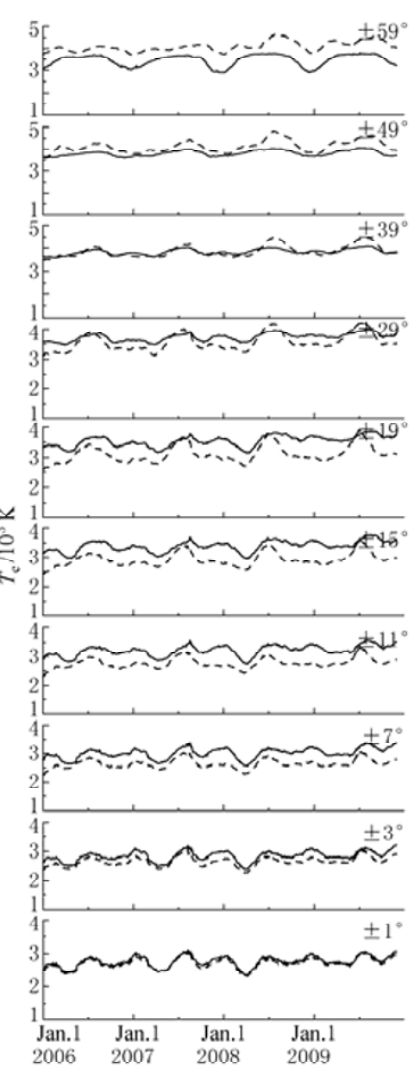

(c)

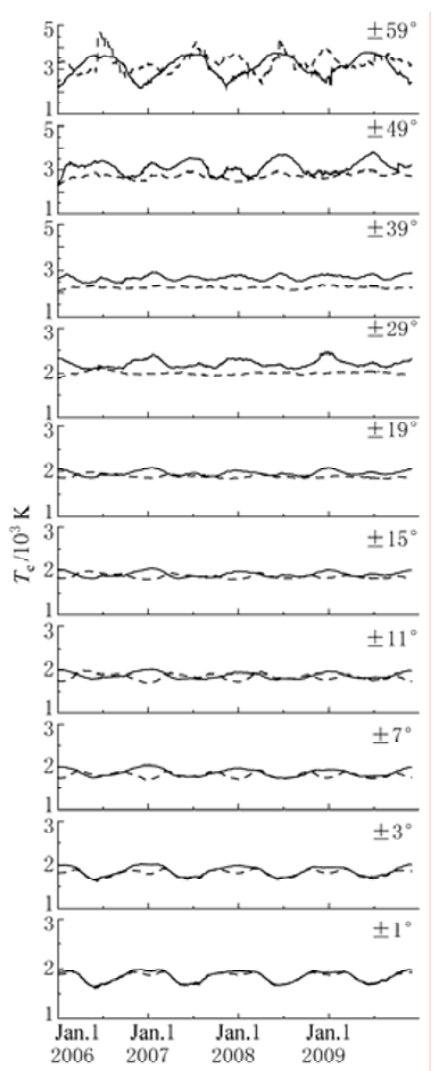

(d)

Figure 5 The yearly variation of electron density in daytime (a); The yearly variation of electron density in nighttime (b); The yearly variation of electron temperature in daytime (c); The yearly variation of electron temperature in nighttime (d). The dashed lines represent the variation in southern hemisphere and the solid lines show the variation in northern hemisphere.

with the result at $600 \mathrm{~km}$ altitude (Bailey et al, 2000). In the southern hemisphere and greater latitudes, the feature disappears gradually with latitude. The 'equinoctial asymmetry' is obviously distinctions among the four years. It is more significant in 2006 and decrease in the following years. As the averages of F107 in the four years are 80.0, 73.1, 69.0 and 70.6, the distinctions may be controlled by the solar activity (e.g. Liu et al, 2006). The 'semiannual anomaly' and the 'equinoctial asymmetry' also apply to the yearly variations of nighttime $N_{\mathrm{e}}$ in the northern hemisphere. The latitude-dependent nighttime $N_{\mathrm{e}}$ is also corresponding to Suo's conclusion (Suo et al, 1989). Suo et al used nighttime observational data from five ground-based ionosonde stations located in China from south to north, to study the F-layer of the ionosphere.

The variations of $T_{\mathrm{e}}$ are displayed in Figures $5 \mathrm{c}$ and $5 \mathrm{~d}$. The yearly variations of $T_{\mathrm{e}}$ in daytime have maxima around the solstices and minima around the equinoxes at low latitude. This is contrary to Bailey et al's (2000) conclusion which used the Hinotori satellite data to study the ionospheric variation at $600 \mathrm{~km}$ altitude. But the results agree well when the latitude is greater $15^{\circ}$ both in southern and northern hemispheres. The yearly variations of nighttime $T_{\mathrm{e}}$ at low latitude have a very interesting feature that the annual component dominates the variation in northern hemisphere (the maxima at December solstice and the minima around the July solstice) and the semiannual component is the basis in southern hemisphere (there are two peaks around the March and September equinox), except two bins on both sides of the geomagnetic equator where the $T_{\mathrm{e}}$ variations are similar. The variation of nighttime $T_{\mathrm{e}}$ between $30^{\circ}$ and $40^{\circ}$ latitude in southern hemisphere have a special phenomena that the feature of the seasonal and annual variations can hardly be identified. As a result, the yearly variation of daytime $T_{\mathrm{e}}$ has a negative correlation with daytime $N_{\mathrm{e}}$ at mid-latitude, but it has a positive correlation when it comes to high latitude.

To investigate the distribution characteristic of the $N_{\mathrm{e}}$ and $T_{\mathrm{e}}$ in different seasons (Spring: February to April; Summer: May to July; Autumn: August to October; 
Winter: November to January), we collect all the data in each bins (there are 65 bins from geomagnetic $-65^{\circ}$ to geomagnetic $65^{\circ}$ ) along $181^{\circ}$ geomagnetic longitude
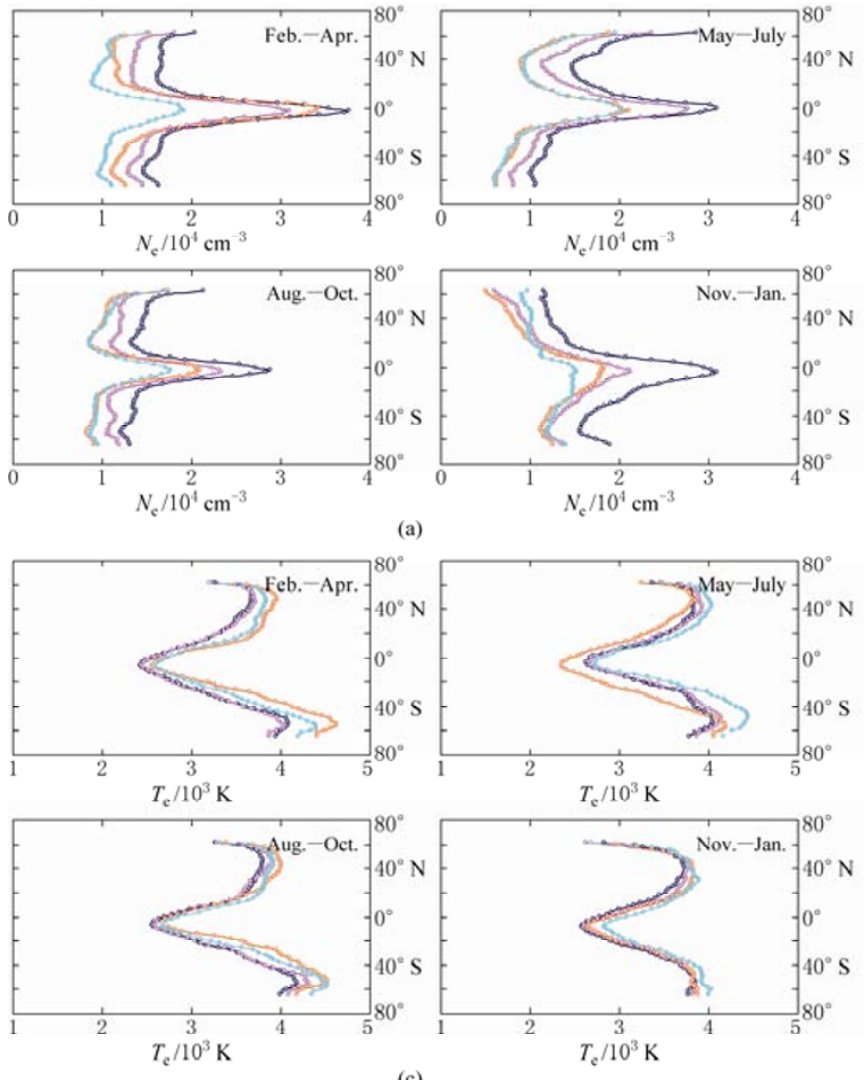

$+2006$ and calculate the average of them. Then the average of the $N_{\mathrm{e}}$ and $T_{\mathrm{e}}$ as a function of the geomagnetic latitude are constructed, as shown in Figure 6.

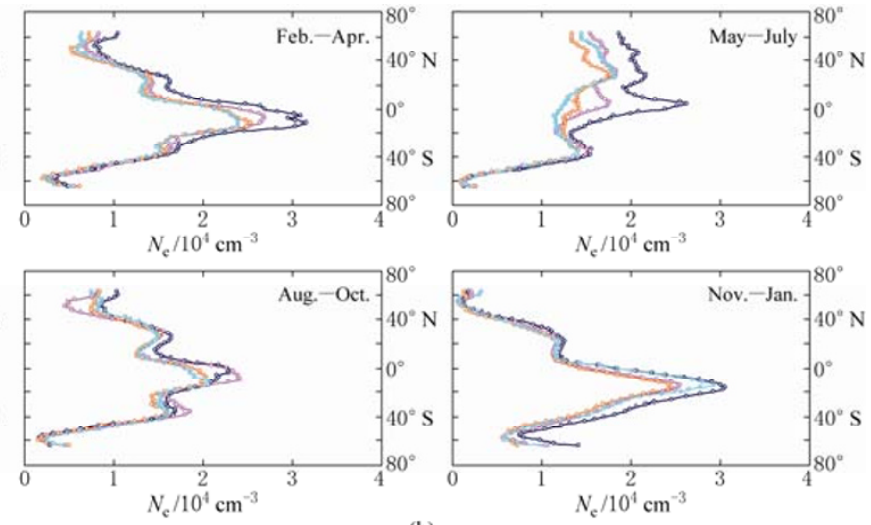

(b)
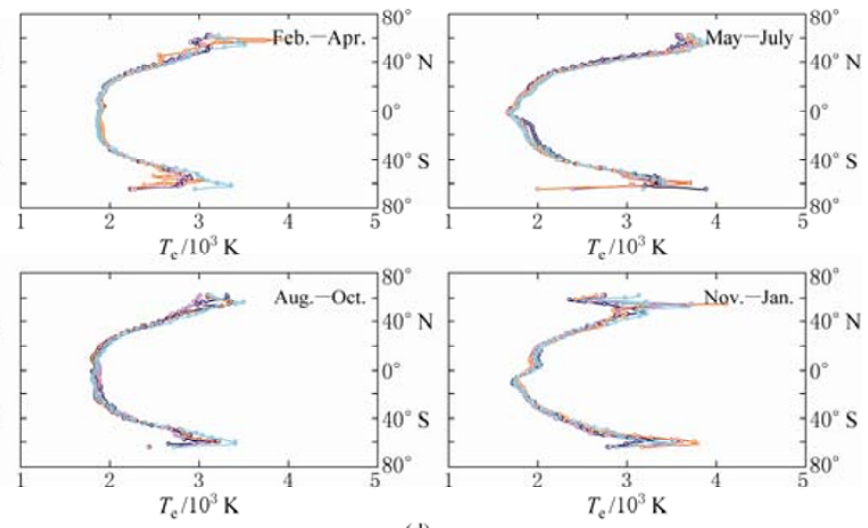

(d)

Figure 6 Distribution of $N_{\mathrm{e}}$ and $T_{\mathrm{e}}$ along the same longitude in four seasons. (a) and b) are respectively $N_{\mathrm{e}}$ in daytime and nighttime; (c) and (d) are $T_{\mathrm{e}}$ in daytime and nighttime.

As shown in Figure 6, $N_{\mathrm{e}}$ has one peak centered close to the magnetic equator both in daytime and nighttime. While in nighttime an asymmetrical distribution about the magnetic equator is observed in summer and winter season, and the shift in mid-latitude can be seen in spring and autumn. The daytime $T_{\mathrm{e}}$ has minima around the magnetic equator and maxima at higher mid-latitude. While the nighttime $T_{\mathrm{e}}$ increase with the latitude. The result is consistent with the conclusion of Ouyang et al's (2008) work.

The ionosphere at low latitudes is highly dynamic. Previous works have shown that the equatorial fountain effect causes the well-known EIA structure, which is characterized by two off-equator peaks of plasma density in the NmF2 region (e.g. Bailey et al, 1981). However, only a single peak centered close to the geomagnetic equator is observed at $660 \mathrm{~km}$ altitude. Since more factors (including local time, season, altitude, solar activity level, spatial position and the other unknown factors) contribute to the variation of topside ionosphere, it is essential to do more work to make these variations clear.

\section{Discussion and conclusions}

After carefully analyzed on the yearly variations of $N_{\mathrm{e}}$ and $T_{\mathrm{e}}$ in 24 given research bins, the conclusions are summarized as follows.

1) There are significant seasonal and annual variations in the variations of $N_{\mathrm{e}}$ and $T_{\mathrm{e}}$.

2) The variations of $N_{\mathrm{e}}$ and $T_{\mathrm{e}}$ in neighboring bins with the same latitude have high correlation.

3) The semiannual anomaly and equinoctial asymmetry exist in the topside ionosphere at low- and mid-latitudes. 
4) The yearly variation of $N_{\mathrm{e}}$ in daytime is opposite to NmF2 at higher latitudes, but in nighttime they are similar.

5) The yearly variation of daytime $T_{\mathrm{e}}$ at $660 \mathrm{~km}$ altitude is contrary to that at $600 \mathrm{~km}$ (Bailey et al, 2000) at low latitude.

6) The nighttime $T_{\mathrm{e}}$ has an obvious annual variation in the northern hemisphere and semiannual variation in the southern hemisphere.

7) The yearly variation of daytime $T_{\mathrm{e}}$ has a negative correlation with daytime $N_{\mathrm{e}}$ at mid-latitude and has a positive correlation with it at high latitudes.

As the variations of the ionosphere are sophisticated, they are subject to diurnal, seasonal, solar cycle, spatial variations and the other unknown factors. To understand and explain these variations, more works are needed to do. The information presented in this paper may help to understand the characteristics of ionospheric variation, to identify and extract the abnormality from the background in events analyzing.

Acknowledgements This study is supported by National Key Technology Research and Development Program (No. 2008BAC35B02). The authors are grateful to the Guest Investigator program issued by CNES for the DEMETER mission for supplying the raw data and thank the reviewers for their constructive comments. The contribution No. is 10FE3006, Institute of Geophyscis, China Earthquake Administration.

\section{References}

Akhoondzadeh M, Parrot M and Saradjian M R (2010). Electron and ion density variations before strong earthquakes $(M>6.0)$ using DEMETER and GPS data. Nat Hazards Earth Syst Sci 10(1): 7-18.

Bailey G J, Fooritt R J and Moffett R J (1981). Latitudinal gradients in the electron temperature of the low $\mathrm{F}$ region at mid to low latitudes. Planet Space Sci 29(2): 171-184, doi:10.1016/0032-0633(81)90031-3.

Bailey G J, Su Y Z and Oyama K I (2000). Yearly variations in the low-latitude topside ionosphere. Ann Geophys 18(7): 789-798.

Balan N, Otsuka Y, Fukao S, Abdu M A and Bailey G J (2000). Annual variations of the ionosphere: a review base on MU radar observations. $A d v$ Space Res 25(1): 153-162.

Chen Y, Liu L, Wan W, Yue X and Su S Y (2009). Solar activeity dependence of the topside ionosphere at low latitudes. J Geophys Res 114: A08306, doi:10.1029/2008JA013957.

Cussac T, Clair M A, Ultre-Guerard P, Buisson F, Lassalle-Balier G, Ledu M, Elisabelar C, Passot X and Rey N (2006). The DEMETER microsatellite and ground segment. Planet Space Sci 54(5): 413-427.

Lebretona J P, Stverak S, Travnicek P, Maksimovic M, Klinge D, Merikallio S, Lagoutte D, Poirier B, Blelly P L, Kozacek Z and Salaquarda (2005). The ISL Langmuir probe experiment processing onboard DEMETER: Scientific objectives, description and first results. Planetary and Space Science 54(5): 472-486.

Liu L, Wan W, Ning B and Zhang M L (2009 b). Climatology of the mean TEC derived from GPS Global Ionospheric Maps. J Geophys Res 114: A06308, doi:10.1029/2009JA014244.
Liu L, Wan W, Ning B, Pirog O M and Kurkin V I (2006). Solar activity variations of the ionospheric peak electron density. J Geophy Res 111: A08304, doi:10.1029/2006JA011598.

Liu L, Wan W, Yue X, Zhao B, Ning B and Zhang M L (2007a). The dependence of plasma density in the topside ionosphere on solar activity level. Ann Geophys 25(6): 1337-1 343.

Liu L, Zhao B, Wan W, Ning B, Zhang M L and He M (2009 a). Seasonal variations of the ionospheric electron densities retrieved from Constellation Observing System for Meteorology, Ionosphere, and Climate mission radio occultation measurements. J Geophys Res 114: A02032, doi:10.1029/2008JA013819.

Liu L, Zhao B, Wan W, Venkartraman S, Zhang M L and Yue X (2007b). Yearly variations of global plasma densities in the topside ionosphere at middle and low latitudes. $J$ Geophys Res 112: A07303, doi: 10.1029/2007JA012283.

Nemec F, Santolík O and Parrot M (2009). Decrease of intensity of ELF/VLF waves observed in the upper ionosphere close to earthquakes: A statistical study. J Geophys Res 114: A04303, doi:10.1029/2008JA013972.

Oliver W L, Kawamura S and Fukao S (2008). The causes of the mid-latitude F layer behavior. J Geophy Res 113: A08310, doi:10.1029/2007JA012590.

Ouyang X Y, Zhang X M, Shen X H, Liu J, Qian J D, Cai J A and Zhao S F (2008). Study on ionospheric $N_{\mathrm{e}}$ disturbances before 2007 Pu'er, Yunnan of China, earthquake. Acta Seismologica Sinica 30(4): 424-436 (in Chinese with English abstract).

Parrot M, Berthelier J J, Lebreton J P, Sauvaud J A, Santolik O and Blecki J (2006). Examples of unusual ionospheric observations made by the DEMETER satellite over seismic regions. Physics and Chemistry of the Earth 31(4-9): 486-495, doi:10.1016/j.pce.2006.02.011.

Rishbeth H (1998). How the thermospheric circulation affects the ionospheric F2-layer. J Atoms Terr Phys 60(14): 1385-1 402.

Rozhnoi A, Solovieva M, Molchanov O, Akentieva O, Berthelier J J, Parrot M, Biagi P F and Hayakawa M (2008). Statistical correlation of spectral broadening in VLF transmitter signal and low-frequency ionospheric turbulence from observation on DEMETER satellite. Nat Hazards Earth Syst Sci 8(5): 1 105-1 111.

Sarkar S, Gwal A K and Parrot M (2007). Ionospheric variations observed by the DEMETER satellite in the mid-latitude region during strong earthquakes. Journal of Atmospheric and Solar-Terrestrial Physics 69(13): 1 524-1540.

Su Y Z, Bailey G J and Oyama K I (1998). Annual and seasonal variations in the low-latitude topside ionosphere. Ann Geophys 16(8): 974-985.

Suo Y C, Li Y S and Wei M J (1989). There is seasonal abnormal phenomenon in night time for $f_{0} F_{2}$. Chinese Journal of Space Science 9(1): 64-69 (in Chinese with English abstract).

Torr M R and Torr D G (1973). The seasonal behavious of the F2-layer of the ionosphere. J Atoms Terr Phys 35: 2237-2 251.

Zhang X M, Qian J D, Ouyang X Y, Shen X H, Liu J, Zhao S F and Guan H P (2008). The variation characteristics of ionospheric $N_{\mathrm{e}}$ above Chinese mainland during quiet magnetic period in summer. Earthquake Reserch in China 24(3): 261-268 (in Chinese with English abstract).

Zhao B, Wan W, Liu L, Mao T, Ren Z, Wang M and Christensen A B (2007). Features of annual and semiannual variations derived from the global ionospheric maps of total electron content. Ann Geophys 25(12): 2 513-2 527.

Zhu R, Yang D M, Jing F, Yang J Y and Ouyang X Y (2008). Ionospheric perturbations before Pu'er earthquake observed on DEMETER. Acta Seismologica Sinica 21(1): 77-81, doi: 10.1007/s11589-008-0077-8.

Zou L, Rishbeth H, Muller-Wodrag I C F, Aylward A D, Millward G H, Fuller-Rowell T J, Idenden D W and Moffett R J (2000). Annual and semiannual variations in the ionospheric F2-layer. I. Modelling. Ann Geophys 18(8): 927-944. 